\title{
Mechanisms of Spica Prunellae against thyroid-associated Ophthalmopathy based on network pharmacology and molecular docking
}

\author{
Yuhan Zhang ${ }^{1,2}$, Xianzhi Li ${ }^{1,2}$, Congcong Guo ${ }^{3}$, Jianjun Dong ${ }^{4^{*}}$ and Lin Liao ${ }^{1,5^{*}}$
}

\begin{abstract}
Background: Thyroid-associated ophthalmopathy (TAO) is an autoimmune inflammatory disorder, which lacks effective treatment currently. Spica Prunellae (SP) is popularly used for its anti-inflammatory and immune-regulating properties, indicating SP may have potential therapeutic value in TAO. Therefore, the purpose of this study is to identify the efficiency and potential mechanism of SP in treating TAO.

Methods: A network pharmacology integrated molecular docking strategy was used to predict the underlying molecular mechanism of treating TAO. Firstly, the active compounds of SP were obtained from TCMSP database and literature research. Then we collected the putative targets of SP and TAO based on multi-sources databases to generate networks. Network topology analysis, GO and KEGG pathway enrichment analysis were performed to screen the key targets and mechanism. Furthermore, molecular docking simulation provided an assessment tool for verifying drug and target binding.

Results: Our results showed that 8 targets (PTGS2, MAPK3, AKT1, TNF, MAPK1, CASP3, IL6, MMP9) were recognized as key therapeutic targets with excellent binding affinity after network analysis and molecular docking-based virtual screening. The results of enrichment analysis suggested that the underlying mechanism was mainly focused on the biological processes and pathways associated with immune inflammation, proliferation, and apoptosis. Notably, the key pathway was considered as the PI3K-AKT signaling pathway.

Conclusion: In summary, the present study elucidates that SP may suppress inflammation and proliferation and promote apoptosis through the PI3K-AKT pathway, which makes SP a potential treatment against TAO. And this study offers new reference points for future experimental research and provides a scientific basis for more widespread clinical application.
\end{abstract}

Keywords: Spica Prunellae, Thyroid-associated ophthalmopathy, TAO, Network pharmacology, Molecular docking

\footnotetext{
* Correspondence: cwc_Il@sdu.edu.cn; liaolin@sdu.edu.cn

${ }^{4}$ Division of Endocrinology, Department of Internal Medicine, Qilu Hospital of

Shandong University, Jinan 250012, China

'Department of Endocrinology and Metabology, Shandong Provincial

Qianfoshan Hospital, Cheeloo College of Medicine, Shandong University,

Jinan 250014, China

Full list of author information is available at the end of the article
}

C C The Author(s). 2020 Open Access This article is licensed under a Creative Commons Attribution 4.0 International License, which permits use, sharing, adaptation, distribution and reproduction in any medium or format, as long as you give appropriate credit to the original author(s) and the source, provide a link to the Creative Commons licence, and indicate if changes were made. The images or other third party material in this article are included in the article's Creative Commons licence, unless indicated otherwise in a credit line to the material. If material is not included in the article's Creative Commons licence and your intended use is not permitted by statutory regulation or exceeds the permitted use, you will need to obtain permission directly from the copyright holder. To view a copy of this licence, visit http://creativecommons.org/licenses/by/4.0/. The Creative Commons Public Domain Dedication waiver (http://creativecommons.org/publicdomain/zero/1.0/) applies to the data made available in this article, unless otherwise stated in a credit line to the data. 


\section{Background}

Thyroid associated ophthalmopathy (TAO), an inflammatory disorder affecting the orbit and ocular adnexa, is occurred in autoimmune thyroid disease, mainly Graves' disease [1]. A prospective study determined that the overall incidence rate of TAO was 10 per 10,000 persons in Europe [2]. And it is reported to occur in $20-30 \%$ of patients with Graves' disease and 2\% of patients with Hashimoto's thyroiditis [3-5]. The pathogenesis of TAO is related to many factors, including genetic factors, environmental factors and autoimmunity, in which autoimmune disorder plays an essential role. An intricate interplay between the potential pathogenic autoantigens and the autoantibodies leads to the activation of autoimmune response and releasing related inflammatory factors, resulting in inflammation of the orbital tissues, abnormal fibroblast proliferation, and extraocular muscle thickening [5-7]. Clinically, it is characterized by proptosis, upper eyelid retraction, restrictive strabismus, exposure keratopathy and other presentation. As a result, its impact on vision and appearance in daily living is significantly associated with the quality of life and psychosocial problem [8-11]. However, current treatments are inadequate due to the incompletely understood pathophysiology of TAO. For mild disease, most patients experience spontaneous recovery within about 6 months [12]. Although helping with symptom management, $13.5 \%$ of patients had a progressively clinical deterioration [13]. For active severe phase, corticosteroids remain the mainstay treatment and orbital radiotherapy commonly serves as an adjuvant therapy [14-16]. However, these therapeutic approaches are often accompanied with limited efficacy and safety concerns, such as hormone resistance and complications [5]. Therefore, there is an urgent demand for novel effective therapy to improve the progression of TAO.

Spica Prunellae (SP), the fruit-spikes of the Prunella vulgaris $L$., is a traditional antipyretic Chinese herb with a wide distribution in Northeast Asia. According to the theory of traditional Chinese medicine (TCM), SP has long been thought to have benefits involving clearing the fire and eyesight, relieving edema and removing stasis. Moreover, SP has been extensively used in food additives and pharmaceuticals [17]. Previous pharmacologic studies indicated that the SP has multiple biological functions such as anti-inflammatory [18], anti-cancer $[19,20]$ and immunomodulatory activities [21]. Nowadays, SP has a wide range of applications in thyroid disease, for instance, thyroid gland swell and subacute thyroiditis [22, 23]. Indeed, some Chinese herbal formulations applied to TAO therapy employ SP as an important ingredient [24]. However, the underlying mechanism is yet to be completely elucidated.

Based on the development of bioinformatics, network biology and pharmacology analysis, network pharmacology becomes a novel strategy to understand the law of interactions between multicomponent and multitarget systematically and comprehensively [25, 26]. In the latest years, network pharmacology has been successfully used to predict the mechanism of TCM in a variety of diseases treatment. Therefore, we adopted the network pharmacology approach to investigate the potential therapeutic targets and pathways of SP in TAO treating, and performed molecular docking studies to further predict the recognition and interaction modes between SP and its predicted targets.

\section{Methods}

\section{Screening of active compounds of SP}

To collect the pharmacologically active compounds of SP, we searched Traditional Chinese Medicine System Pharmacology Database [27] (TCMSP, http://lsp.nwu. edu.cn/tcmsp.php), a systematic pharmacology platform of Chinese herbal medicine. Based on their ADME (absorption, distribution, metabolism and excretion) features, Oral bioavailability (OB) and Drug-likeness (DL) were set as the key parameters [28]. OB refers to the percentage of which the pharmaceutical agents is used and unchanged throughout systemic circulation [29]. And DL is a concept of optimize pharmacokinetics and properties [30]. Then, based on the threshold values of OB $30 \%$ and DL 0.18 [31], eleven active compounds were selected. In addition, five researches [32-36] using high-performance liquid chromatography (HPLC) to identify active compounds of SP were screened through literature search. After integrating with the results obtained from TCMSP, total twenty active compounds of SP were used to the subsequent network pharmacology study.

\section{Prediction of putative targets of SP}

The putative targets of active compounds were extracted from the TCMSP database [27] (http://lsp.nwu.edu.cn/ tcmsp.php), the PubChem database [37] (http://pubchem.ncbi.nlm.nih.gov), the Swiss Target Prediction database [38] (http://www.swisstargetprediction.ch/), and the STITCH database [39] (http://stitch.embl.de/). Then, all the targets names were put into uniprot sites (http:// www.uniprot.org/) and selected by Homo Saipan species to normalize the gene information. Detailed information of putative targets is provided in Table S1.

\section{Identification of TAO related targets}

Related TAO targets were gathered from multi-sources databases using "Thyroid-associated ophthalmopathy" and "graves ophthalmopathy" as keywords. Five database are as follow: (1) the Therapeutic Target Database [40] (TTD, https://db.idrblab.org/ttd/); (2) the Online Mendelian Inheritance in Man database [41] (OMIM, http:// 
omim.org/); (3) the Comparative Toxicogenomics Database [42] (CTD, http://ctdbase.org/); (4) the DrugBank database [43] (https://www.drugbank.ca/); (5) the GeneCards database [44] (https://www.genecards.org/). Detailed information is described in Table S2 and Table S3.

\section{Analysis of overlapping targets of SP in TAO Target mapping}

To obtain the candidate targets responsible for TAO therapy, the putative targets of SP mapped to the TAO related targets to obtain overlapping targets. For overlapping targets, numbers were visualized with a Venn diagram generated in $\mathrm{R}$ version 3.2.0, a freely available, open-source statistical programming language and environment for statistical computing [45], with VennDiagram package.

\section{Protein-protein interaction (PPI) analysis}

These related targets of SP in treating TAO were then put in STRING tools [46] (https://string-db.org/), an online platform that critically predict functional protein association networks, to generate protein interaction network. Network data were used for the topological properties analysis to identify important targets in antiTAO system, and Table S4 for more information.

\section{Gene ontology (GO) and KEGG pathway enrichment analysis}

To further reveal the potential mechanism of SP in TAO treating, we imported overlapping targets into the Functional Annotation tool of Database for Annotation, Visualization and Integrated Discovery (DAVID) 6.8 [47] (https://david.ncifcrf.gov/) to perform GO functional analysis and KEGG pathways analysis. The enrichment $P$ values of functional annotations were corrected by both Bonferroni $(P<0.05)$ and Benjamini $(P<0.05)$ correction. The plots of GO enrichment and KEGG pathway enrichment were then carried out with $\mathrm{R}$ version 3.2.0.

\section{Network construction}

The Cytoscape3.6.1 [48] (http://cytoscape.org/), a software environment for integrated models of biomolecular interaction networks, was utilized to construct the following networks:(1) Compound-target network; (2) PPI network of TAO targets; (3) PPI network of compoundTAO targets; (4) Compound-target-pathway network.

The Cytoscape plug-in Network Analyzer was applied to analyze the topological properties of the PPI network. Three indices were used to assess the topological properties of every node. (1) "Degree" refers to the number of nodes that directly interact with that node in a network [49], (2) "Betweenness Centrality": the proportion of the number of nodes that have passed through the shortest path in a network [50], with important influence due to their control over information passing between other nosdes. Thus, the betweenness reflects its global importance, while the degree measures the local importance of a node; (3) "Closeness Centrality" reflects the closeness of a node to other nodes [51]. The level of these three paraments reflects the topological importance of the node in a network, which the higher the values are, the more important the nodes are. The targets with degree $>$ twofold median were selected as the hub genes and used for further molecular docking.

\section{Molecular docking simulation Target protein preparation}

The crystal structures of hub genes were downloaded from RCSB Protein Data Bank [52] (http://www.pdb.org/ ). The downloaded complexes were embellished by PyMol2.3.0 (the PyMol Molecular Graphics System) to remove original ligand, water molecules and phosphates. Moreover, the AutoDock Tools1.5.6 [53] (http:// mgltools.scripps.edu/documentation/links/autodock) was used to prepare receptors, including adding hydrogen and seting docking paraments. "Grid box" was set to maximum to perform the blind docking.

\section{Ligand preparation}

Before docking, the 2D structures of compounds were drawn using the ChemBioDraw13.0 software. Then the ChemBio3D13.0 software was used to transfer the 2D structure to $3 \mathrm{D}$ chemical structure and make energy minimizing for the further docking.

\section{Molecular docking}

All ligand and receptor files were saved as pdbqt format. Then we used Autodock Vina [54], a freely available open-source packages, to evaluate and verify the binding affinity of compound-target relationship, and the prediction results from network pharmacology. The binding models were visualized by PyMol2.3.0 software and Discovery Studio3.5 software.

\section{Results}

\section{Compound-target network}

A flowchart of the network pharmacology study is summarized in Fig. 1. Based on TCMSP, 11 active compounds were selected by the screen criteria of $\mathrm{OB}$ and DL. Considering the large number of researches performed HPLC to identify the major active components of SP, we conducted the literature search in Pubmed and China National Knowledge Infrastructure (CNKI). And nine compounds were supplemented accounting for the relatively large proportion and proven active role in SP, including Betulinic acid, Caffeic acid, Corosolic acid, Euscaphic acid, Maslinic acid, Rosmarinic acid, Rutin, Oleanolic acid and Ursolic acid (Table 1). Then 


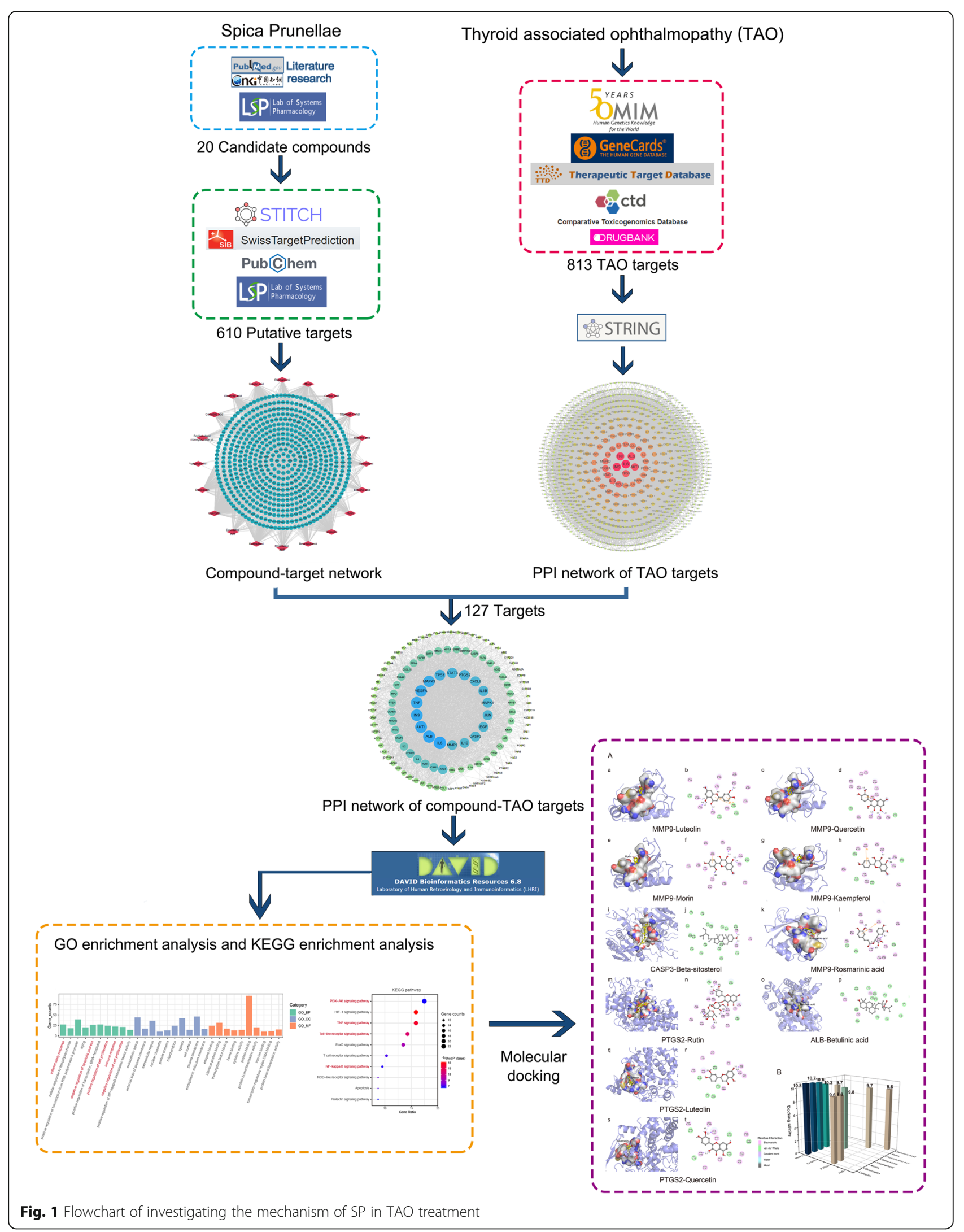


Table 1 Chemical information for the active compounds of SP

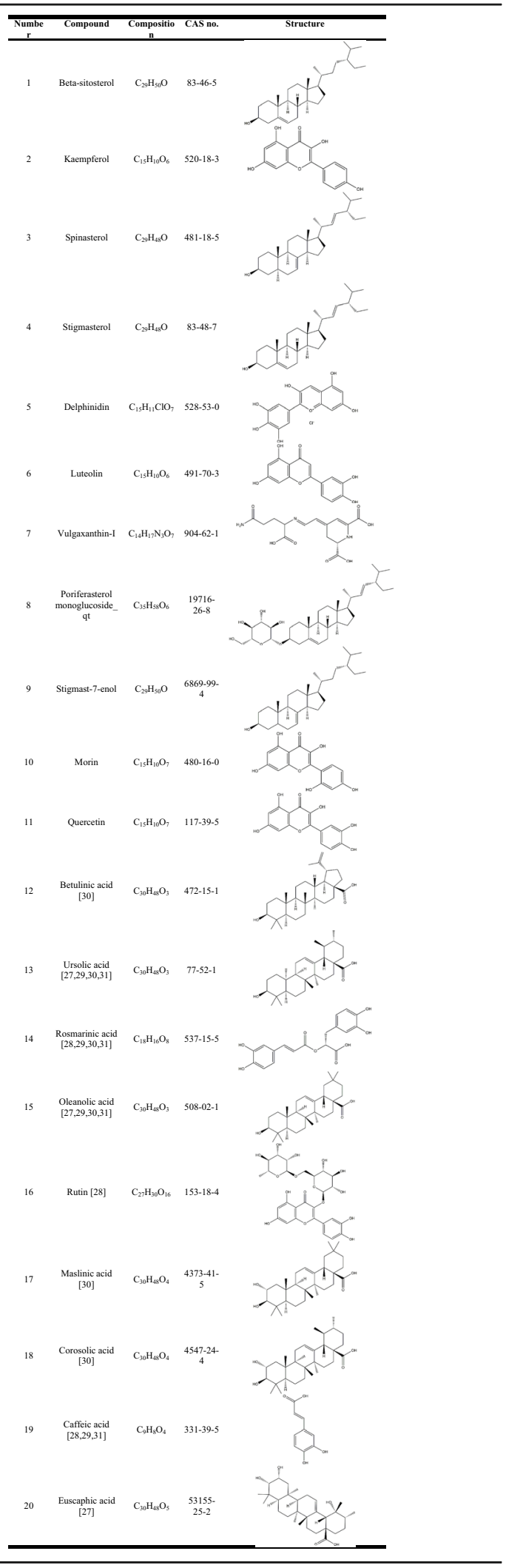

we identified 610 putative targets from TCMSP, Pubchem, STITCH and SwissTargetPrediction, which the detailed information is described in Table S1. To obtain further understanding of the relationship between the 20 compounds and their corresponding targets on a system level, we conducted the compound-target network (Fig. 2a). In a network topology analysis, we identified top six compounds adopting the average degree (103.94) as the threshold value: Quercetin (degree $=298$ ), Ursolic acid $($ degree $=155)$, Luteolin $($ degree $=149)$, Kaempferol $($ degree $=146)$, Morin $($ degree $=135)$ and Delphinidin $($ degree $=113)$.

\section{TAO target network}

In the present study, a total of 813 proteins were documented as the disease potential targets of TAO (Table S2). As shown in Fig. 2b, the PPI network reflected the interaction between these targets. Six targets highly related to the pathological process of $\mathrm{TAO}$, which were sorted according to the node degree, including IL6 (interleukin-6, degree $=262$ ), INS (insulin, degree $=247$ ), TNF (tumor necrosis factor, degree $=242$ ), ALB (serum albumin, degree $=229)$, AKT1 $($ RAC-alpha serine/threonine-protein kinase, degree $=221$ ) and TP53 (tumor protein p53, degree $=205)($ Table S3).

\section{PPI network of compound-TAO targets}

Based on the above results, the 610 putative targets of SP mapped to the 813 TAO related targets to obtain overlapping targets. Consequently, 127 targets were identified as the candidate targets responsible for TAO therapy (Fig. 3a). A PPI network was then constructed to evaluate the role of the targets in complex disease and discover the interactive effects. After analyzing the topological feature of the abovementioned PPI network, 127 genes were sorted in descending order by degree in Table S4 with an average degree of 36.74 . As shown in Fig. 3b, nodes arranged in a concentric circle according to the degree and the innermost center circle is composed of 18 hub nodes, including AKT1, ALB, CASP3 (caspase-3), CXCL8 (interleukin-8), EGF (epidermal growth factor), IL10 (interleukin-10), IL1B (interleukin-1 beta), IL6, INS, JUN (transcription factor AP-1), MAPK1 (mitogen-activated protein kinase 1), MAPK3 (mitogen-activated protein kinase 3), MMP9 (matrix metallopeptidase 9), PTGS2 (prostaglandin-endoperoxide synthase 2), STAT3 (signal transducer and activator of transcription 3), TP53 and VEGFA (vascular endothelial growth factor A). These hub genes are of significance in the network and used for the following molecular docking study.

\section{GO and KEGG pathway enrichment analysis}

To further elucidate the mechanism of drug treatment systematically, the enrichment analysis was performed 

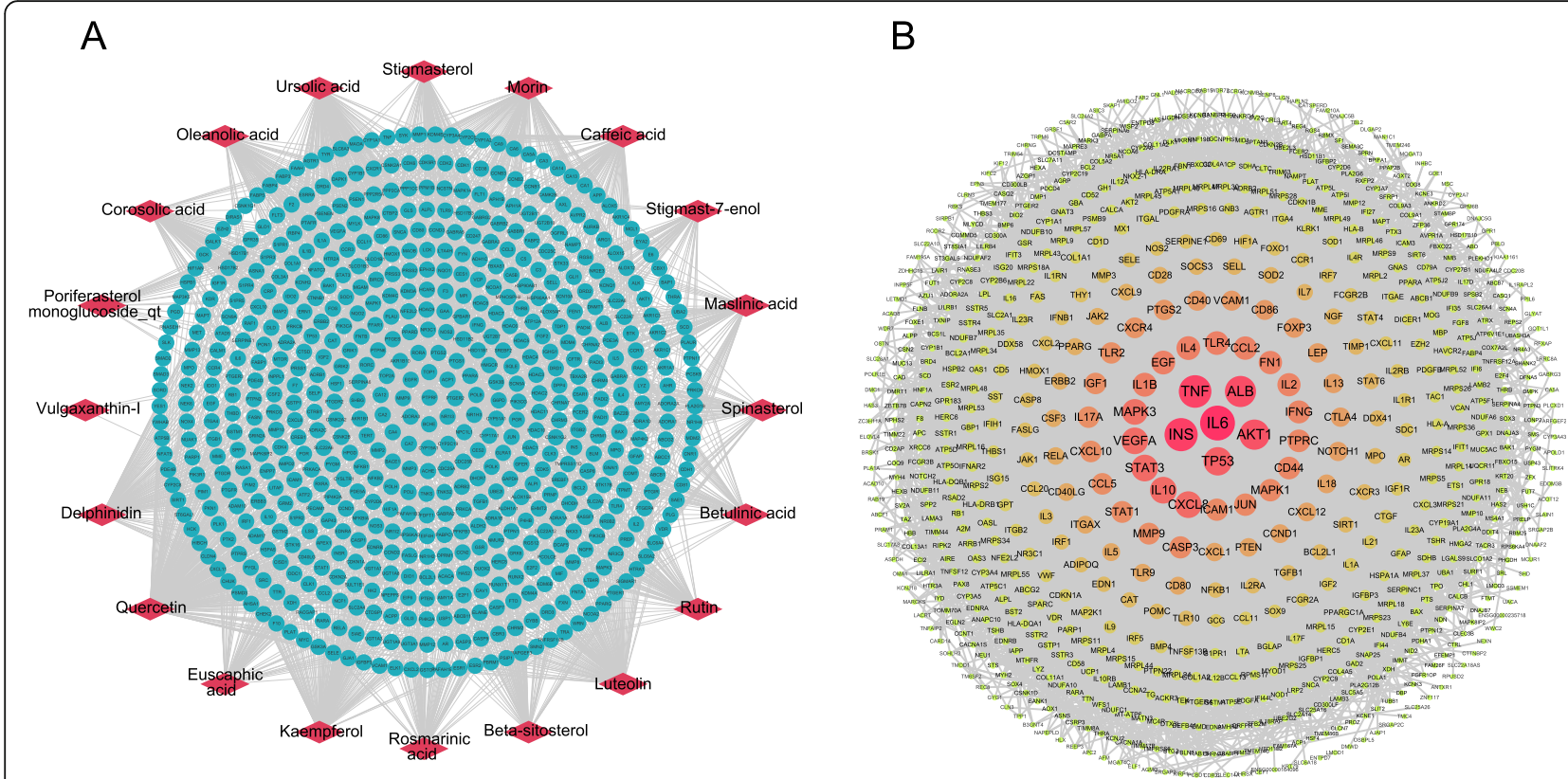

Fig. 2 Compound-target network and PPI network of TAO targets. a Compound-target network. Red diamond nodes represent active compounds of SP and blue circular nodes represent corresponding targets. $\mathbf{b}$ PPI network of TAO targets. The sizes and colors of the nodes are illustrated from big to small and green to red in descending order of degree values

with DAVID on 127 genes. The top 10 GO items and KEGG pathways are selected based on counts of hit genes and $P$ values (Fig. 4). For biological processes, it can be found that the targets were mainly enriched in inflammatory response (GO:0006954, GO:0071222, GO:
0051092), cell proliferation (GO:0008284, GO:0008285), apoptosis (GO:0043066) and immune response (GO: 0006955). Additionally, the other three functional annotations are associated with transcriptional regulation (GO:0045944, GO:0045893) and aging (GO:0007568).
A

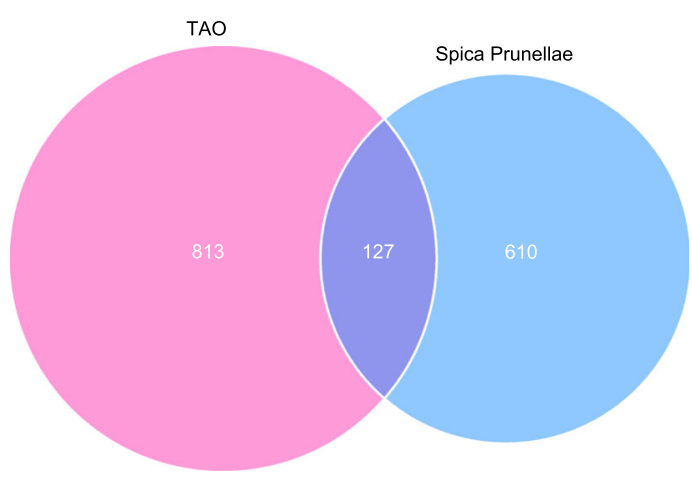

B

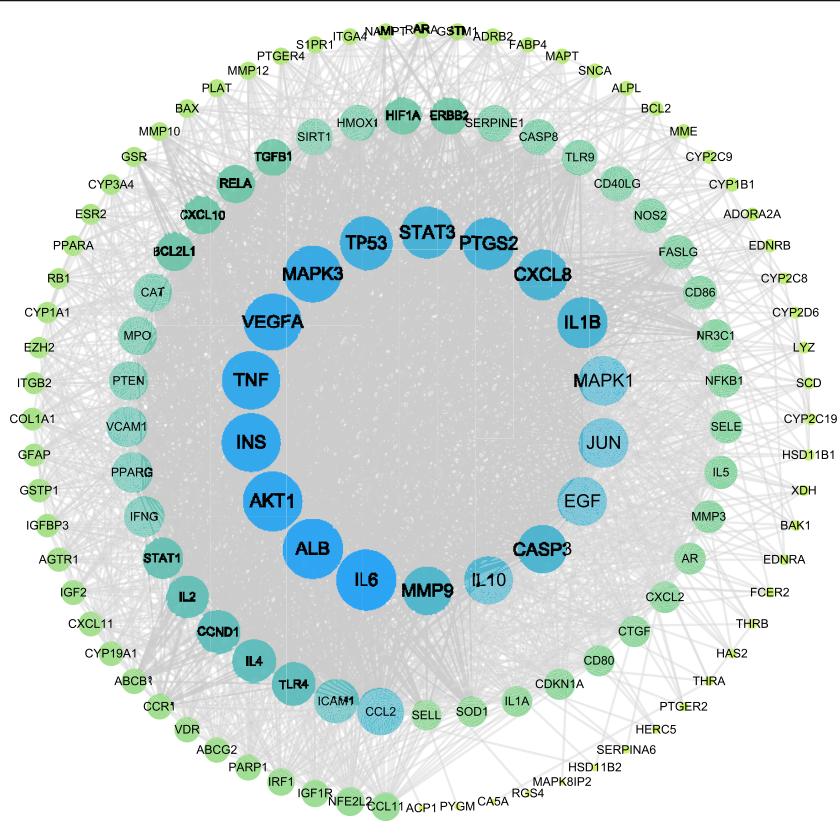

Fig. 3 Venn diagram and PPI network of compound-TAO targets. a Venn diagram of intersecting targets of SP and TAO. b PPI network of compound-TAO targets. The sizes and colors of the nodes are illustrated from big to small and green to blue in descending order of degree values 


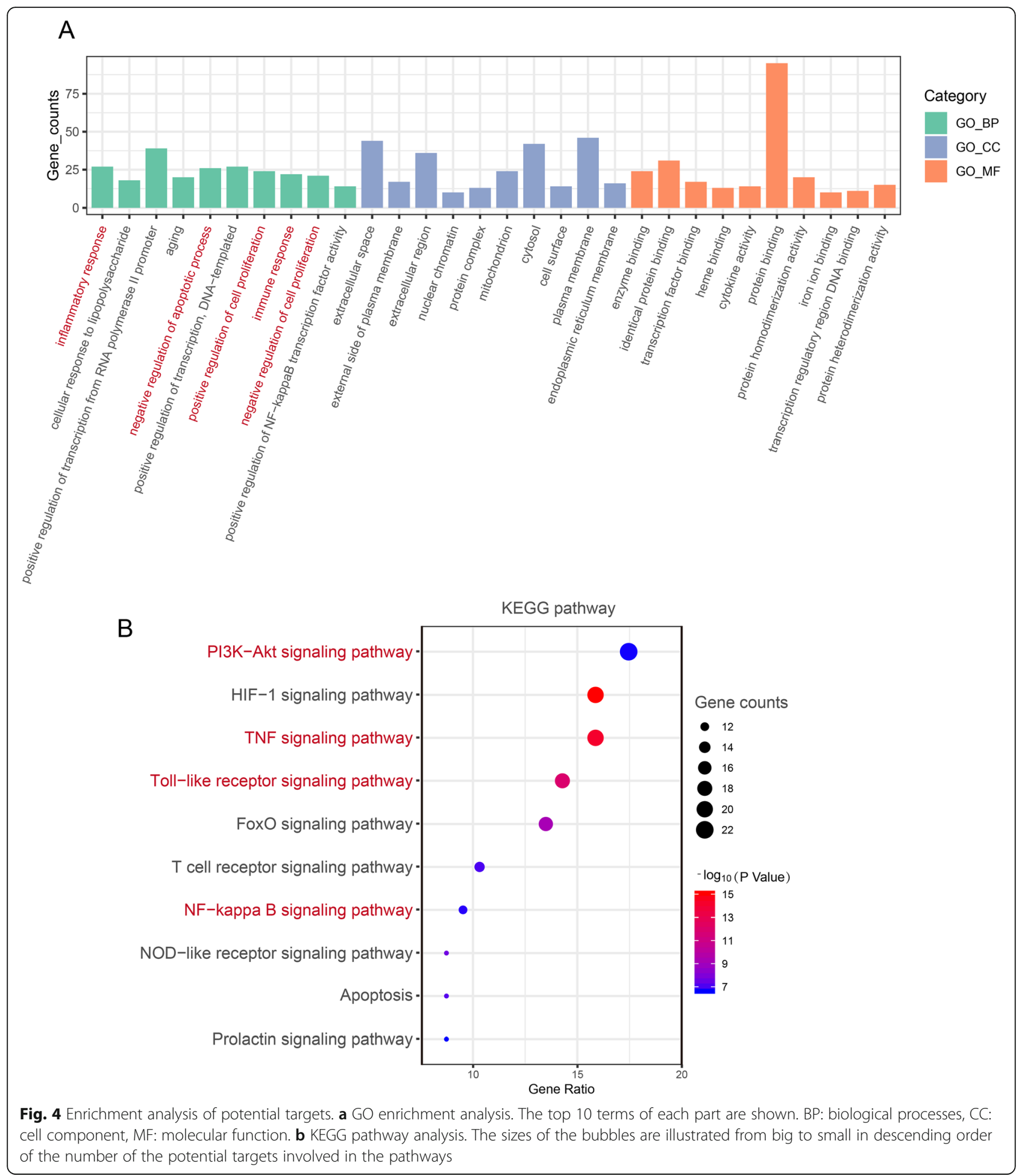

For pathway analysis, most involved in immune and inflammatory related pathways such as PI3K-AKT signaling pathway (hsa04151), NOD-like receptor signaling pathway (hsa04621), Toll-like receptor signaling pathway (hsa04620), NF-kappa B signaling pathway (hsa04064) and TNF signaling pathway (hsa04668) (Table 2). These results demonstrated that the main action mechanism underlying TAO treatment.

\section{Molecular docking analysis}

In the present studies, the possible interaction activity between 18 hub genes and their corresponding 
Table $\mathbf{2}$ Information for top 10 pathways

\begin{tabular}{lllll}
\hline Number & Pathway name & Count & Corresponding hub genes & $P$ Value \\
\hline 1 & PI3K-Akt signaling pathway & 22 & AKT1, EGF, IL6, INS, MAPK1, MAPK3, TP53, VEGFA & $2.25 E-07$ \\
2 & HIF-1 signaling pathway & 20 & AKT1, EGF, IL6, INS, MAPK1, MAPK3, STAT3, VEGFA & 8.24E-16 \\
3 & TNF signaling pathway & 20 & AKT1, CASP3, IL1B, IL6, JUN, MAPK1, MAPK3, MMP9, PTGS2, TNF & 7.25E-15 \\
4 & Toll-like receptor signaling pathway & 18 & AKT1, CXCL8, IL1B, IL6, JUN, MAPK1, MAPK3, TNF & $1.23 E-12$ \\
5 & FoxO signaling pathway & 17 & AKT1, EGF, IL10, IL6, INS, MAPK1, MAPK3, STAT3 & 5.82E-10 \\
6 & T cell receptor signaling pathway & 13 & AKT1, IL10, JUN, MAPK1, MAPK3, TNF & $8.99 E-08$ \\
7 & NF-KB signaling pathway & 12 & CXCL8, IL1B, PTGS2, TNF & $1.85 E-07$ \\
8 & NOD-like receptor signaling pathway & 11 & CXCL8, IL1B, IL6, MAPK1, MAPK3, TNF & $2.33 E-08$ \\
9 & Apoptosis & 11 & CASP3, TNF, TP53, AKT1 & $6.48 E-08$ \\
10 & Prolactin signaling pathway & 11 & AKT1, INS, MAPK1, MAPK3, STAT3 & $2.45 E-07$ \\
\hline
\end{tabular}

compounds of SP was investigated with molecular docking verification. Meanwhlie, the retrieved targets and active compounds were further filtered by the docking affinity values reported by AutoDock Vina. There were total seventy-three pairs delivered into the docking simulation (Table 3). The greater the absolute value of the docking affinity, the stronger binding ability between the compounds and the active site of the targets. Among the docking results, most binding complexes possessed high binding affinity with an average of $-8.1 \mathrm{kcal} / \mathrm{mol}$. The modes of top 10 binding complexes are displayed in Fig. 5, including MMP9-Luteolin docking $(-10.8 \mathrm{kcal} / \mathrm{mol})$, MMP9-Quercetin docking $(-19.7 \mathrm{kcal} / \mathrm{mol})$, MMP9Morin docking $(-10.6 \mathrm{kcal} / \mathrm{mol})$, MMP9-Kaempferol ($10.2 \mathrm{kcal} / \mathrm{mol})$, CASP3-Beta-sitosterol docking $(-9.8 \mathrm{kcal} /$ $\mathrm{mol})$, MMP9- Rosmarinic acid docking $(-9.7 \mathrm{kcal} / \mathrm{mol})$, PTGS2-Rutin docking $(-9.7 \mathrm{kcal} / \mathrm{mol})$, ALB-Betulinic acid docking $(-9.6 \mathrm{kcal} / \mathrm{mol})$, PTGS2-Luteolin $(-9.6 \mathrm{kcal} /$ $\mathrm{mol})$, PTGS2-Quercetin $(-9.6 \mathrm{kcal} / \mathrm{mol})$. For concreteness, taking the MMP9-Luteolin docking as an example, small molecule ligand Luteolin could potentially fit into the interface pocket formed by interaction amino acid residues in protein (Fig. 5A (a)). It showed that six hydrogen bond formation between ligand and residues invloved in LEU 188, ALA 189, GLN 227, TYR 248 and MET 247. Three hydrogen bond interactions were considered as strong interaction with the distance of 3.2, 3.3, $3.5 \AA$ respectively. Moreover, HIS 226 residue contributed to form two pi-pi stacking interactions with two benzene rings of ligand. The other essential residues (GLY 186, LEU 187, VAL 223, ARG 249, LEU 222, LEU 243, ALA 242, TYR 245 and PRO 246) interacted with Luteolin through electrostatic forces, van der Waals forces, etc. (Fig. $5 \mathrm{~A}(\mathrm{~b})$ ). Consequently, Luteolin stably binded to MMP9 protein bonds through mutiple interaction forces. Overall, we found that hydrogen bond and electrostatic forces were the main forms of interactions of the top 10 docking complexes, and the diverse of the interaction forms determined the ability of binding affinity.

\section{Compound-target -pathway network}

As shown in Fig. 6A, a compound-hub gene-pathway network was established by connecting potential pathways, compounds and hub genes. To find the major nodes, we took the average of respective degree as the threshold values to identify the significant compounds and targets. Three compounds and 8 targets were selected as core nodes in anti-TAO system: Quercetin (degree $=14$ ), Ursolic acid (degree $=11)$ and Rutin (degree $=8)$, PTGS2 $($ degree $=17)$, MAPK3 $($ degree $=14)$, AKT1 $($ degree $=13)$, TNF $($ degree $=13)$, MAPK1 $($ degree $=10)$, CASP3 $($ degree $=$ 9), IL6 (degree =9) and MMP9 (degree =9). Subsequently, for a more detailed explanation of the associations described above, we extracted a subnetwork to exhibit the core nodes and key mapping pathways (Fig. 6b).

\section{Discussion}

In recent years, there has been growing researches devoted to drug discovery and combined treatment with TCM against complex disease such as TAO, in which the network pharmacology approach plays an essential role. In the present study, we constructed the following network to reveal the potential targets and pathways of SP in TAO treatment: compound-target network, PPI network of TAO targets, PPI network of compoundTAO targets and compound-target -pathway network.

After integrating and consolidating information from diverse sources of available databases, 20 active compounds of SP acted on 127 different targets associated with TAO. According to the compound-target network, six compounds and putative targets are highly connected and can be defined as vital compounds in SP. Previous studies have indicated the anti-inflammatory, proapoptosis and immunomodulation effects of Quercetin [55, 56], Ursolic acid [57-59], Luteolin [60-62], Kaempferol [63-65], Morin [66, 67] and Delphinidin [68, 69] in various diseases, suggesting SP may exhibit beneficial effects in TAO which is characterized by immunoinflammatory response. Actually, the PPI network of TAO 
Table 3 Results of 18 hub genes and compounds of SP molecular docking

\begin{tabular}{|c|c|c|c|c|}
\hline Number & Hub genes & PDB ID & Compound & Docking affinity (kcal/mol) \\
\hline \multirow[t]{5}{*}{1} & \multirow[t]{5}{*}{ AKT1 } & \multirow[t]{5}{*}{$4 \mathrm{EKL}$} & Luteolin & -8.6 \\
\hline & & & Delphinidin & -8.4 \\
\hline & & & Quercetin & -8.2 \\
\hline & & & Kaempferol & -8.0 \\
\hline & & & Morin & -7.9 \\
\hline 2 & ALB & 1E7E & Betulinic acid & -9.6 \\
\hline \multirow[t]{7}{*}{3} & \multirow[t]{7}{*}{ CASP3 } & \multirow[t]{7}{*}{ 3GJQ } & Beta-sitosterol & -9.8 \\
\hline & & & Ursolic acid & -9.1 \\
\hline & & & Oleanolic acid & -8.8 \\
\hline & & & Rutin & -8.8 \\
\hline & & & Rosmarinic acid & -8.2 \\
\hline & & & Quercetin & -7.7 \\
\hline & & & Morin & -7.6 \\
\hline \multirow[t]{2}{*}{4} & \multirow[t]{2}{*}{ CXCL8 } & \multirow[t]{2}{*}{$5 \mathrm{WDZ}$} & Rutin & -6.9 \\
\hline & & & Quercetin & -6.4 \\
\hline 5 & EGF & $2 \mathrm{KV} 4$ & Quercetin & -6.9 \\
\hline 6 & IL 10 & $1 Y 6 K$ & Quercetin & -6.9 \\
\hline \multirow[t]{3}{*}{7} & \multirow[t]{3}{*}{$\mathrm{IL} 1 \mathrm{~B}$} & \multirow[t]{3}{*}{$5 B \bigvee P$} & Ursolic acid & -7.6 \\
\hline & & & Rutin & -7.3 \\
\hline & & & Quercetin & -7.0 \\
\hline \multirow[t]{3}{*}{8} & \multirow[t]{3}{*}{ IL6 } & \multirow[t]{3}{*}{$4 \mathrm{O} \mathrm{H}$} & Rutin & -7.3 \\
\hline & & & Ursolic acid & -7.2 \\
\hline & & & Quercetin & -7.1 \\
\hline 9 & INS & 5USV & Rutin & -4.8 \\
\hline \multirow[t]{4}{*}{10} & \multirow[t]{4}{*}{ JUN } & \multirow[t]{4}{*}{$1 J U N$} & Ursolic acid & -6.2 \\
\hline & & & Rosmarinic acid & -5.9 \\
\hline & & & Beta-sitosterol & -5.7 \\
\hline & & & Quercetin & -5.5 \\
\hline \multirow[t]{2}{*}{11} & \multirow[t]{2}{*}{ MAPK1 } & \multirow[t]{2}{*}{ 6RQ4 } & Quercetin & -9.2 \\
\hline & & & Caffeic acid & -6.5 \\
\hline \multirow[t]{6}{*}{12} & \multirow[t]{6}{*}{ MAPK3 } & \multirow[t]{6}{*}{$2 \mathrm{ZOQ}$} & Maslinic acid & -9.4 \\
\hline & & & Corosolic acid & -9.1 \\
\hline & & & Ursolic acid & -9.0 \\
\hline & & & Spinasterol & -8.7 \\
\hline & & & Oleanolic acid & -8.6 \\
\hline & & & Stigmast-7-enol & -7.8 \\
\hline 13 & MMP9 & $6 \mathrm{ESM}$ & Luteolin & -10.8 \\
\hline & & & Quercetin & -10.7 \\
\hline & & & Morin & -10.6 \\
\hline & & & Kaempferol & -10.2 \\
\hline & & & Rosmarinic acid & -9.7 \\
\hline & & & Delphinidin & -8.9 \\
\hline & & & Caffeic acid & -8.0 \\
\hline & & & Ursolic acid & -7.8 \\
\hline
\end{tabular}


Table 3 Results of 18 hub genes and compounds of SP molecular docking (Continued)

\begin{tabular}{|c|c|c|c|c|}
\hline Number & Hub genes & PDB ID & Compound & Docking affinity (kcal/mol) \\
\hline \multirow[t]{15}{*}{14} & PTGS2 & $5 F 19$ & Rutin & -9.7 \\
\hline & & & Luteolin & -9.6 \\
\hline & & & Quercetin & -9.6 \\
\hline & & & Kaempferol & -9.4 \\
\hline & & & Maslinic acid & -9.3 \\
\hline & & & Corosolic acid & -9.2 \\
\hline & & & Delphinidin & -9.2 \\
\hline & & & Oleanolic acid & -9.1 \\
\hline & & & Betulinic acid & -8.6 \\
\hline & & & Stigmasterol & -8.5 \\
\hline & & & Vulgaxanthin-I & -8.5 \\
\hline & & & Ursolic acid & -8.4 \\
\hline & & & Beta-sitosterol & -8.3 \\
\hline & & & Euscaphic acid & -8.3 \\
\hline & & & Caffeic acid & -7.3 \\
\hline \multirow[t]{3}{*}{15} & STAT3 & 6 NJS & Poriferasterol monoglucoside_qt & -8.1 \\
\hline & & & Ursolic acid & -7.9 \\
\hline & & & Caffeic acid & -6.1 \\
\hline \multirow[t]{6}{*}{16} & TNF & $5 \mathrm{M} 2 \mathrm{~J}$ & Rutin & -8.1 \\
\hline & & & Euscaphic acid & -8.0 \\
\hline & & & Quercetin & -8.0 \\
\hline & & & Ursolic acid & -7.9 \\
\hline & & & Rosmarinic acid & -7.5 \\
\hline & & & Caffeic acid & -6.2 \\
\hline \multirow[t]{2}{*}{17} & TP53 & $6 \mathrm{SI3}$ & Quercetin & -8.0 \\
\hline & & & Ursolic acid & -7.7 \\
\hline \multirow[t]{3}{*}{18} & VEGFA & IVPF & Ursolic acid & -8.2 \\
\hline & & & Delphinidin & -7.6 \\
\hline & & & Quercetin & -7.4 \\
\hline
\end{tabular}

targets did reflect the underlying pathogenesis of TAO, which are consistent with prior researches. Commonly reported mechanism [6] is the promotion and mutual interaction of these including that cellular immunity and humoral immunity mainly caused by massive activation of $\mathrm{T}$ lymphocytes, inflammatory response and proliferation of orbital fibroblasts. This manifests as an uncontrolled secretion of inflammatory cytokines and growth factors by activated orbital fibroblasts, leading to orbital tissue remodeling and enlargement. Further, to better elucidate the mechanism of SP in treating TAO, the 127 targets were screened for 18 hub genes in the PPI network of compound-TAO targets. Coincidentally, there are 6 targets considered as key pathogenic gene in the PPI network of TAO targets, which are involved in the 18 hub genes, namely TNF, ALB, IL6, INS, AKT1 and
TP53, reconfirming SP might possess good effects on TAO.

According to the compound-hub gene-pathway network, Quercetin, Ursolic acid and Rutin interacted with the large number of targets, indicating the important roles in the anti-TAO system. Quercetin is a flavonoid phytoestrogen exhibiting antioxidant and anti-inflammatory properties and reducing proliferation in orbital fibroblasts [70-72]. In addition to the above effects, Ursolic acid [5759] and Rutin [73, 74] are reported to promote apoptosis and regulate immune in other cell systems and animal models. Eight important therapeutic targets with the degree $>7.83$ are PTGS2, MAPK3, AKT1, TNF, MAPK1, CASP3, IL6 and MMP9. Meanwhile, we performed molecular docking simulation between 18 hub genes and 20 active compounds to complement key targets. The results 


\section{A}
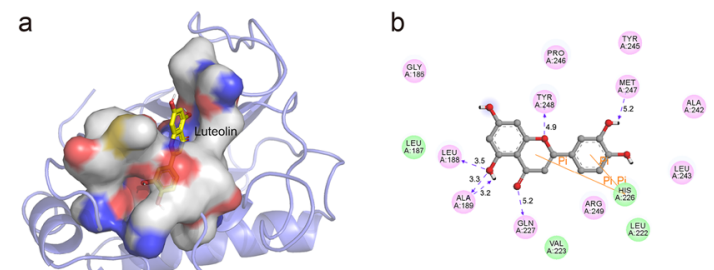

MMP9-Luteolin
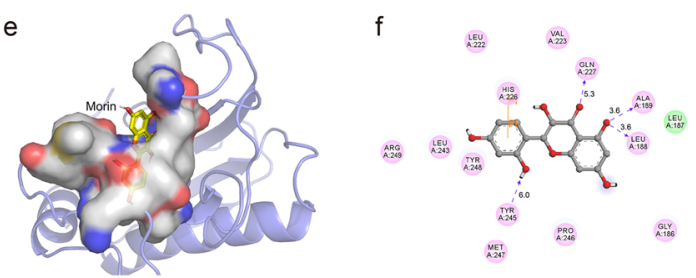

MMP9-Morin
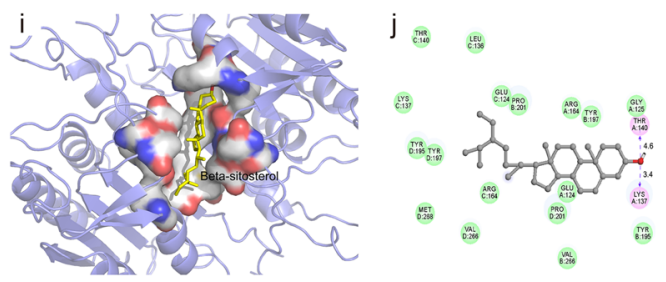

CASP3-Beta-sitosterol

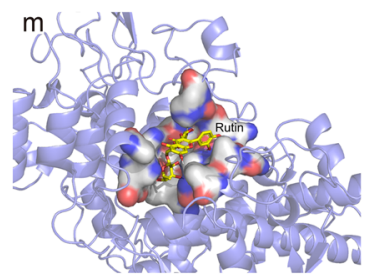

$\mathrm{n}$

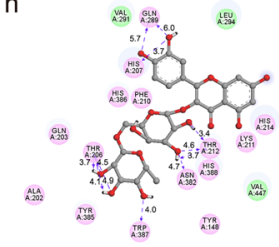

PTGS2-Rutin

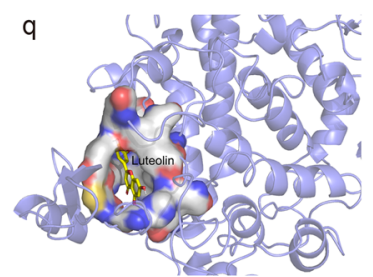

$$
\text { 성 }
$$

PTGS2-Luteolin
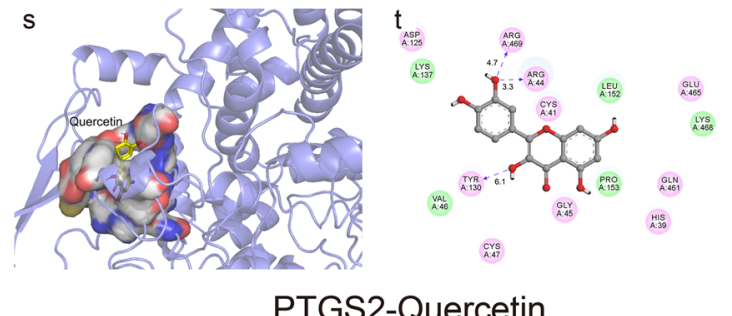
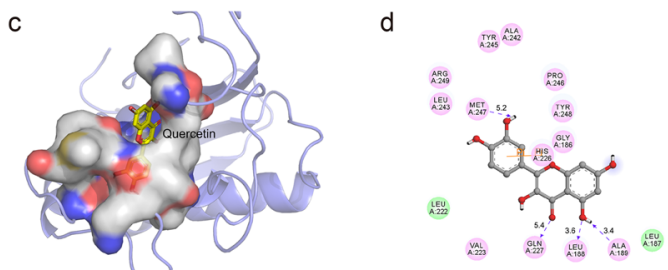

\section{MMP9-Quercetin}

g

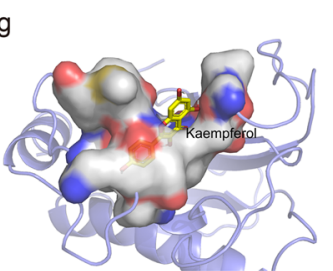

$\mathrm{h}$

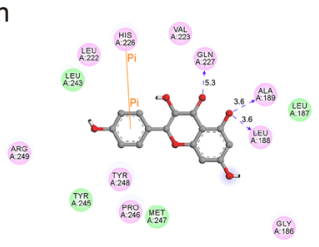

MMP9-Kaempferol
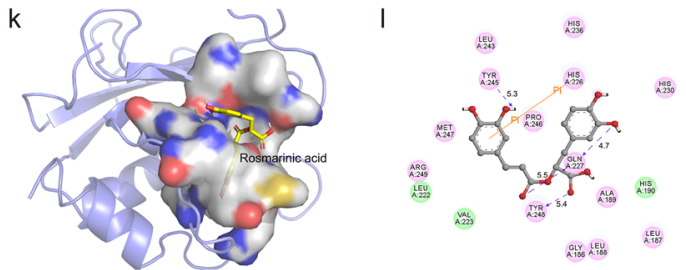

MMP9-Rosmarinic acid
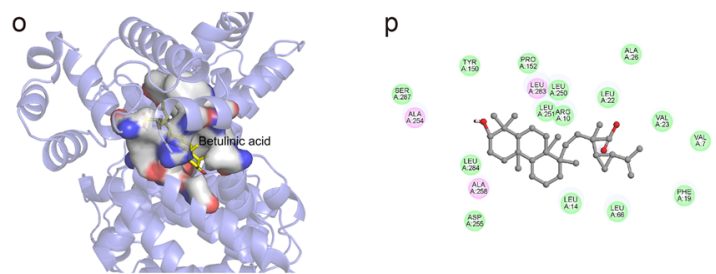

ALB-Betulinic acid

B

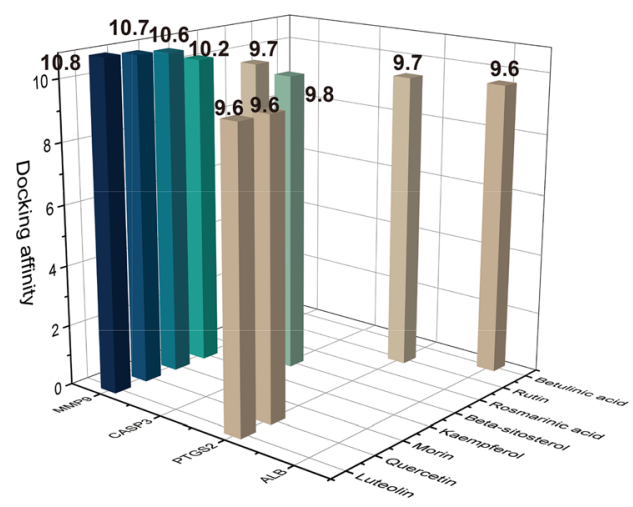

Fig. 5 (See legend on next page.) 
(See figure on previous page.)

Fig. 5 Molecular docking models of active compounds binding to potential targets. a The top 10 pairs of molecular docking simulation are shown. Schematics (3D) represent that molecular model of the compound is in the binding pocket of the protein. The compounds are shown as stick model with yellow colored. The amino acid residues surrounding are represented by surface. Schematics (2D) show the interactions between compounds and surrounding residues. The purple dashed lines represent hydrogen bonds and the interaction distances are indicated beside to the bonds. The orange lines demarcate pi-pi stacking interactions. $\mathbf{b} 3 \mathrm{D}$ column diagram shows the affinity of 10 pairs docking models. $X$-axis: protein names, Y-axis: active compounds, Z-axis: the absolute value of the docking affinity

suggested that all of the target-compound pairs possess good docking affinity, especially, MMP9, PTGS2, CASP3 and ALB. ALB is the most abundant protein in human plasma, to which drugs usually bind, playing a crucial importance to understand the pharmacodynamics and pharmacokinetics [75]. Beyond that, the drop in ALB level reflects the oxidative stress damage [76], albeit not confirmed in TAO pathogenesis. We therefore speculate that the good affinity of ALB and Betulinic acid may refer to the general drug response rather than the treatment mechanism of SP. Consequently, SP plays a beneficial role in TAO, at least in part, through modulating PTGS2, MAPK3, AKT1, TNF, MAPK1, CASP3, IL6 and MMP9. GO functional annotation and pathway enrichment analysis further supported the potential therapeutic mechanism, the results of which was predominated by immune inflammation, proliferation and apoptosis.

In terms of immune inflammation, proinflammatory cytokine PTGS2, IL6 and TNF were validated the participation in TAO onset. PTGS2 is involved in prostaglandin biosynthesis, which have been ascribed key role in inflammation [77]. Prior studies have noted that PTGS2 diminished with a decrease in clinical activity score in TAO $[78,79]$, is currently believed to be pivotal to inflammatory process in TAO patients. IL6 has been implicated in the pathogenesis of autoimmune disease [80]. It has been reported that AKT1/NF-kB signaling pathway contributed to the production of IL6 in the retrobulbar space in active phase of TAO [81]. Likewise, research showed that the elevation levels of TNF in serum is mediated by AKT1/NF- $k B$ signaling pathway in inflammatory response of TAO [82]. At present, there has been reported some inhibitors of TNF obtained promising results in patients with $\mathrm{TAO}$, irrespective of rare adverse effects [83]. Then SP with TNF as a key therapeutic target may have potential to be an effective agent for TAO. Hence, it is possible that SP could suppress the inflammatory cytokines secretion of $\mathrm{T}$ lymphocytes and orbital fibroblasts through AKT1/NF-kB signaling pathway.

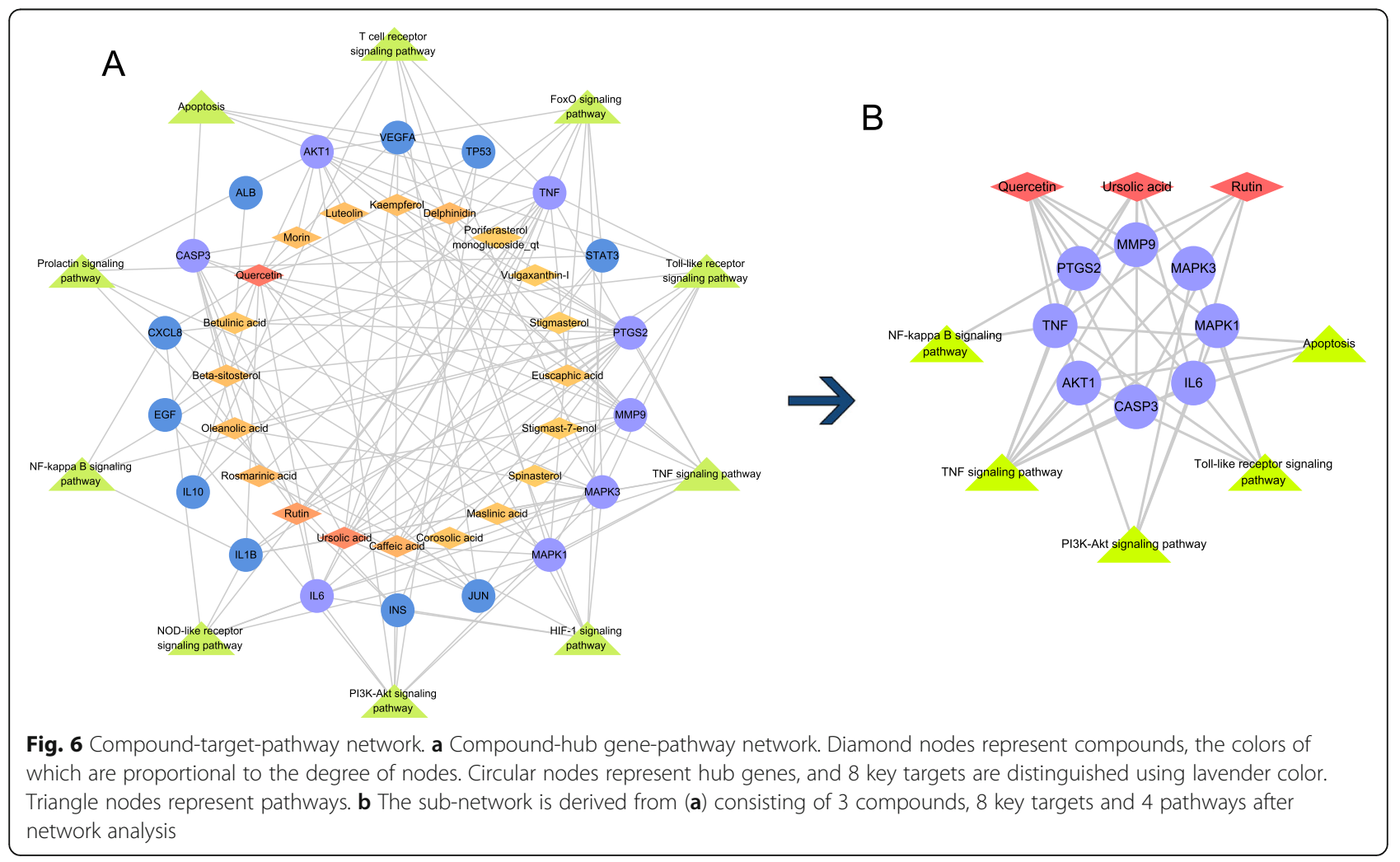




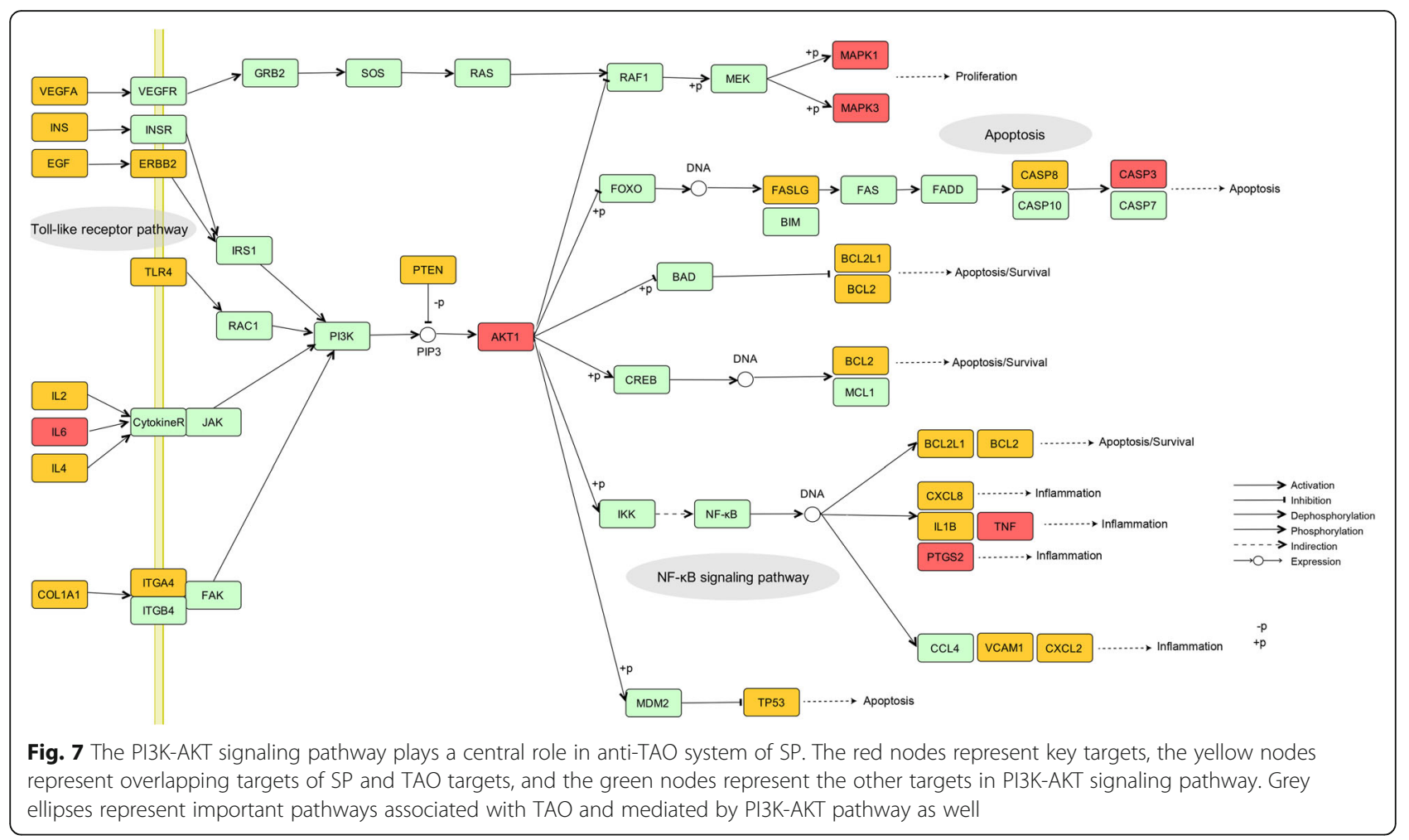

Regarding whether SP could modulate immune like corticosteroids exerts [83], for instance, decrease antigen presentation to $\mathrm{T}$ lymphocytes in $\mathrm{TAO}$, it requires further laboratory investigation.

For proliferation and apoptosis, PI3K-AKT signaling pathway seems to be significant in mediating cell growth and death in TAO. Recently studies demonstrated that orbital fibrocytes express thyrotropin receptor (TSHR) [84] and activation of TSHR leads to increased inflammatory gene expression and proliferation through PI3KAKT pathway [85-87]. Besides this, the increased cell proliferation of orbital preadipocytes is also contributed in TAO progression [88]. CASP3 activation is one of the final steps in the execution of apoptosis, which is activated in orbital preadipocytes by some compounds in TAO [88]. And SP exhibits pro-apoptotic actions via activation of CASP3 in various cancer [89]. Although there is a lack of relevant studies of MAPK1, MAPK3 in TAO, they act in a signaling cascade that regulates various cellular processes such as proliferation and apoptosis [90]. MMP9 as a kind of matrix metalloproteinases has been proved to participate in inflammation of multiple tumors through TNF signaling pathway [91]. However, it still requires further researches to elucidate the role of MMP9 in TAO pathogenesis. Therefore, it can be summarized from the results that whether in immune inflammation or proliferation and apoptosis, the PI3K-AKT signaling pathway plays a key role in TAO, and inhibition of this process could be an effective therapeutic target for SP against TAO (Fig. 7).

\section{Conclusion}

In conclusion, up till now, TAO treatments have been an intractable problem, but TCM may be a potential alternative treatment to a certain extent. In the present study, we predicted 8 key targets from complex networks through the integration of network pharmacology and molecular docking, and performed comprehensive explanation of the therapeutic mechanism of SP in TAO, which is likely to focus on three aspects: immunoinflammatory suppression and regulation of proliferation and apoptosis. In addition, we found that PI3K-AKT signaling pathway may occupy core status in anti-TAO system. Our research would be enlightening for developing therapeutic methods targeted TAO. However, further extensive experiments will be necessary to unravel the above possibility, such as in vivo and in vitro efficacy experiments of SP in TAO therapy.

\section{Supplementary information}

Supplementary information accompanies this paper at https://doi.org/10 1186/s12906-020-03022-2.

Additional file 1: Table S1 The putative targets of SP. 
Additional file 2: Table S2 TAO related targets

Additional file 3: Table S3 Information for TAO targets after PPI analysis. Additional file 4: Table S4 Information for overlapped targets after PPI analysis.

\section{Abbreviations}

ALA: Alanine; ARG: Arginine; BP: Biological processes; CC: Cellular component; CNKI: China National Knowledge Infrastructure Database; DL: Drug-likeness; GLN: Glutamine; GLY: Glycine; GO: Gene Ontology; HPLC: High-performance liquid chromatography; KEGG: Kyoto Encyclopedia of Genes and Genomes; LEU: Leucine; MET: Methionine; MF: Molecular function; OB: Oral bioavailability; PDB: Protein Data Bank; PPI: Protein-protein interaction; PRO: Proline; SP: Spica Prunellae; TAO: Thyroid-associated ophthalmopathy; TCM: Traditional Chinese medicine; TSHR: Thyrotropin receptor; TYR: Tyrosine; VAL: Valine

\section{Acknowledgements \\ Not applicable.}

\section{Authors' contributions}

YHZ conceived and design this study. $L L$ and JJD supervised the findings of this work. YHZ, XZL and CCG performed the research, analyzed the data wrote the draft of the manuscript. The authors contribute to review and approve the final version of the manuscript.

\section{Funding}

This work was funded by National Natural Science Foundation of China (No. 81770822).

\section{Availability of data and materials}

All data generated or analyzed during this study are available from public databases, published articles and supplementary materials.

\section{Ethics approval and consent to participate}

Not applicable.

\section{Consent for publication}

Not applicable.

\section{Competing interests}

The authors declare that they have no competing interests.

\section{Author details}

${ }^{1}$ Department of Endocrinology and Metabology, Shandong Provincial Qianfoshan Hospital, Cheeloo College of Medicine, Shandong University, Jinan 250014, China. ${ }^{2}$ Laboratory of Endocrinology, Medical Research Center, Shandong Provincial Qianfoshan Hospital, the First Affiliated Hospital of Shandong First Medical University, Jinan 250014, Shandong, China. ${ }^{3}$ Department of Endocrinology, Affiliated Hospital of Shandong University of Traditional Chinese Medicine, Jinan 250011, China. ${ }^{4}$ Division of Endocrinology, Department of Internal Medicine, Qilu Hospital of Shandong University, Jinan 250012, China. ${ }^{5}$ Department of Endocrinology and Metabology, the First Affiliated Hospital of Shandong First Medical University, Ji-nan 250014, China.

Received: 17 April 2020 Accepted: 9 July 2020

Published online: 20 July 2020

\section{References}

1. Garrity JA, Bahn RS. Pathogenesis of graves Ophthalmopathy. Implications for prediction, prevention, and treatment. Am J Ophthalmol. 2006;142(1): 147-153.e142

2. Perros P, Hegedus L, Bartalena L, Marcocci C, Kahaly GJ, Baldeschi L, et al. Graves' orbitopathy as a rare disease in Europe: a European group on Graves' Orbitopathy (EUGOGO) position statement. Orphanet J Rare Dis. 2017:12(1):72.

3. Lim SL, Lim AK, Mumtaz M, Hussein E, Wan Bebakar WM, Khir AS Prevalence, risk factors, and clinical features of thyroid-associated ophthalmopathy in multiethnic Malaysian patients with Graves' disease. Thyroid. 2008;18(12):1297-301.
4. Abraham-Nordling M, Bystrom K, Torring O, Lantz M, Berg G, Calissendorff J, et al. Incidence of hyperthyroidism in Sweden. Eur J Endocrinol. 2011;165(6): 899-905.

5. Sahli E, Gunduz K. Thyroid-associated Ophthalmopathy. Turk J Ophthalmol. 2017:47(2):94-105.

6. Shan SJ, Douglas RS. The pathophysiology of thyroid eye disease. J Neuroophthalmol. 2014;34(2):177-85.

7. Maheshwari R, Weis E. Thyroid associated orbitopathy. Indian J Ophthalmol. 2012;60(2):87-93.

8. Coulter I, Frewin S, Krassas GE, Perros P. Psychological implications of graves' orbitopathy. Eur J Endocrinol. 2007;157(2):127-31.

9. Park JJ, Sullivan TJ, Mortimer RH, Wagenaar M, Perry-Keene DA. Assessing quality of life in Australian patients with Graves' ophthalmopathy. Br J Ophthalmol. 2004;88(1):75-8.

10. Weng CY, Li ZF, Hu SD, Luo YS, Feng XT, Zhong Q, et al. Evaluation of quality of life in patients with graves orbitopathy and its influencing factors. Zhonghua Nei Ke Za Zhi. 2019;58(8):577-83.

11. Wickwar S, McBain HB, Ezra DG, Hirani SP, Rose GE, Newman SP. What are the psychosocial outcomes of treatment for thyroid eye disease? A systematic review. Thyroid. 2014;24(9):1407-18.

12. Genere N, Stan MN. Current and emerging treatment strategies for graves' Orbitopathy. Drugs. 2019;79(2):109-24.

13. Perros P, Crombie AL, Kendall-Taylor P. Natural history of thyroid associated ophthalmopathy. Clin Endocrinol (Oxf). 1995;42(1):45-50.

14. Bartalena L, Krassas GE, Wiersinga W, Marcocci C, Salvi M, Daumerie C, et al. Efficacy and safety of three different cumulative doses of intravenous methylprednisolone for moderate to severe and active Graves' orbitopathy. J Clin Endocrinol Metab. 2012;97(12):4454-63.

15. Godfrey KJ, Kazim M. Radiotherapy for active thyroid eye disease. Ophthal Plast Recons. 2018;34(4S Suppl 1):S98-S104.

16. Smith TJ, Hegedus L. Graves' disease. N Engl J Med. 2016;375(16):1552-65.

17. Guo $Q$, Chen Y. Textual research on original plant and dietotherapy history of Prunella vulgaris. Zhongguo Zhong Yao Za Zhi. 2011;36(21):3057-62.

18. Ryu SY, Oak MH, Yoon SK, Cho DI, Yoo GS, Kim TS, et al. Anti-allergic and anti-inflammatory triterpenes from the herb of Prunella vulgaris. Planta Med. 2000;66(4):358-60.

19. Fang Y, Zhang L, Feng J, Lin W, Cai Q, Peng J. Spica Prunellae extract suppresses the growth of human colon carcinoma cells by targeting multiple oncogenes via activating miR-34a. Oncol Rep. 2017;38(3):1895-901.

20. Yin DT, Lei $M, X u J$, Li H, Wang Y, Liu Z, et al. The Chinese herb Prunella vulgaris promotes apoptosis in human well-differentiated thyroid carcinoma cells via the B-cell lymphoma-2/Bcl-2-associated X protein/caspase-3 signaling pathway. Oncol Lett. 2017;14(2):1309-14.

21. Sun HX, Qin F, Pan YJ. In vitro and in vivo immunosuppressive activity of Spica Prunellae ethanol extract on the immune responses in mice. J Ethnopharmacol. 2005;101(1-3):31-6.

22. Li F, Wu Y, Chen L, Hu L, Liu X. Initial treatment combined with Prunella vulgaris reduced prednisolone consumption for patients with subacute thyroiditis. Ann Transl Med. 2019;7(3):45.

23. Yang K, Guo KQ, Wu HY. Clinical effect of Prunellae Oral liquid on goiter with different thyroid function. Chin J integrated Trad Western Med. 2007:27(1):37-9.

24. Hong J, Zheng S. Study on the medicacation rule of thyroid-associated opthhaimopathy with the help of traditional Cinese medicine inheritance supporting platform. Asia-Pacific Trad Med. 2019;15(4):169-72.

25. Hopkins AL. Network pharmacology. The next paradigm in drug discovery. Nat Chem Biol. 2008;4(11):682-90.

26. Aguayo-Orozco A, Audouze K, Brunak S, Taboureau O. In silico systems pharmacology to assess Drug's therapeutic and toxic effects. Curr Pharm Des. 2016;22(46):6895-902.

27. Ru J, Li P, Wang J, Zhou W, Li B, Huang C, et al. TCMSP: a database of systems pharmacology for drug discovery from herbal medicines. J Chem. 2014;6:13.

28. Liu H, Wang J, Zhou W, Wang Y, Yang L. Systems approaches and polypharmacology for drug discovery from herbal medicines: an example using licorice. J Ethnopharmacol. 2013;146(3):773-93.

29. Varma MV, Obach RS, Rotter C, Miller HR, Chang G, Steyn SJ, et al. Physicochemical space for optimum oral bioavailability: contribution of human intestinal absorption and first-pass elimination. J Med Chem. 2010; 53(3):1098-108.

30. Tao W, Xu X, Wang X, Li B, Wang Y, Li Y, et al. Network pharmacologybased prediction of the active ingredients and potential targets of Chinese 
herbal radix Curcumae formula for application to cardiovascular disease. J Ethnopharmacol. 2013;145(1):1-10.

31. Yang $\mathrm{H}$, Zhang W, Huang C, Zhou W, Yao Y, Wang Z, et al. A novel systems pharmacology model for herbal medicine injection: a case using Reduning injection. BMC Complement Altern Med. 2014;14:430.

32. Lee MK, Ahn YM, Lee KR, Jung JH, Jung OS, Hong J. Development of a validated liquid chromatographic method for the quality control of Prunellae Spica: determination of triterpenic acids. Anal Chim Acta. 2009;633(2):271-7.

33. Liang J, Zhang L, Yan X. Identification of the major chemical constituents of Prunella Vulgaris L. by HPLC-ESI-MS/MS. Chin Med Modern Distance Educ China. 2013;11(14):153-4.

34. Tang G. Determination of active ingredients in Chinese medicine prunella vulgaris by high performance liquid chromatography. J North Pharmacy. 2016;13(4):4-5.

35. Yang J, Hu YJ, Yu BY, Qi J. Integrating qualitative and quantitative characterization of Prunellae Spica by HPLC-QTOF/MS and HPLC-ELSD. Chin J Nat Med. 2016;14(5):391-400

36. Zhai $X$, Wu X, Xu X, Gao X. Determination of active ingredients in Chinese medicine Prunella Spica by high performance liquid chromatography. World Latest Med Inform. 2019;19(69):118.

37. Kim S, Chen J, Cheng T, Gindulyte A, He J, He S, et al. PubChem 2019 update: improved access to chemical data. Nucleic Acids Res. 2019;47(D1):D1 102-9.

38. Gfeller D, Grosdidier A, Wirth M, Daina A, Michielin O, Zoete V. SwissTargetPrediction: a web server for target prediction of bioactive small molecules. Nucleic Acids Res. 2014;42(Web Server issue):W32-8.

39. Szklarczyk D, Santos A, von Mering C, Jensen L, Bork P, Kuhn M. STITCH 5: augmenting protein-chemical interaction networks with tissue and affinity data. Nucleic Acids Res. 2016;44(D1):D380-4.

40. Chen X, Ji ZL, Chen YZ. TTD. Therapeutic target database. Nucleic Acids Res. 2002;30(1):412-5.

41. Boyadjiev SA, Jabs EW. Online Mendelian inheritance in man (OMIM) as a knowledgebase for human developmental disorders. Clin Genet. 2000;57(4): 253-66.

42. Grondin CJ, Davis AP, Wiegers TC, Wiegers JA, Mattingly CJ. Accessing an expanded exposure science module at the comparative Toxicogenomics database. Environ Health Perspect. 2018;126(1):014501.

43. Wishart DS, Knox C, Guo AC, Cheng D, Shrivastava S, Tzur D, et al. DrugBank: a knowledgebase for drugs, drug actions and drug targets. Nucleic Acids Res. 2008;36(Database issue):D901-6.

44. Rebhan M, Chalifa-Caspi V, Prilusky J, Lancet D. GeneCards: a novel functional genomics compendium with automated data mining and query reformulation support. Bioinformatics. 1998;14(8):656-64.

45. Team RDC. R. a language and environment for statistical computing. Vienna: R Foundation for Statistical Computing; 2011. http://www.R-project.org.

46. Szklarczyk D, Morris JH, Cook H, Kuhn M, Wyder S, Simonovic M, et al. The STRING database in 2017: quality-controlled protein-protein association networks, made broadly accessible. Nucleic Acids Res. 2017;45(D1):D362-8.

47. Huang DW, Sherman BT, Lempicki RA. Systematic and integrative analysis of large gene lists using DAVID bioinformatics resources. Nat Protoc. 2008;4(1): 44-57.

48. Shannon P. Cytoscape: a software environment for integrated models of biomolecular interaction networks. Genome Res. 2003;13(11):2498-504.

49. Missiuro PV, Liu K, Zou L, Ross BC, Zhao G, Liu JS, et al. Information flow analysis of interactome networks. PLoS Comput Biol. 2009;5(4):e1000350.

50. Raman K, Damaraju N, Joshi GK. The organisational structure of protein networks: revisiting the centrality-lethality hypothesis. Syst Synth Biol. 2014; 8(1):73-81.

51. Zhang Y, Bai M, Zhang B, Liu C, Guo Q, Sun Y, et al. Uncovering pharmacological mechanisms of Wu-tou decoction acting on rheumatoid arthritis through systems approaches: drug-target prediction, network analysis and experimental validation. Sci Rep. 2015;5:9463.

52. Liu H, Wang L, Lv M, Pei R, Li P, Pei Z, et al. AlzPlatform: an Alzheimer's disease domain-specific chemogenomics knowledgebase for polypharmacology and target identification research. J Chem Inf Model. 2014;54(4):1050-60.

53. Morris GM, Huey R, Lindstrom W, Sanner MF, Belew RK, Goodsell DS, et al. AutoDock4 and AutoDockTools4: automated docking with selective receptor flexibility. J Comput Chem. 2009;30(16):2785-91.

54. Trott O, Olson AJ. AutoDock Vina: improving the speed and accuracy of docking with a new scoring function, efficient optimization, and multithreading. J Comput Chem. 2010;31 (2):455-61.
55. Belviranli M, Okudan N. Well-Known Antioxidants and Newcomers in Sport Nutrition: Coenzyme Q10, Quercetin, Resveratrol, Pterostilbene, Pycnogenol and Astaxanthin. In: Lamprecht M, ed. Antioxidants in Sport Nutrition. Boca Raton (FL): CRC Press/Taylor \& Francis; 2015.

56. Zhu S, Wang H, Zhang J, Yu C, Liu C, Sun H, et al. Antiasthmatic activity of quercetin glycosides in neonatal asthmatic rats. 3 Biotech. 2019;9(5):189.

57. Lin JH, Chen SY, Lu CC, Lin JA, Yen GC. Ursolic acid promotes apoptosis, autophagy, and chemosensitivity in gemcitabine-resistant human pancreatic cancer cells. Phytother Res. 2020.

58. Mukonowenzou NC, Dangarembizi R, Chivandi E, Nkomozepi P, Erlwanger KH. Administration of ursolic acid to new-born pups prevents dietary fructose-induced non-alcoholic fatty liver disease in Sprague Dawley rats. J Dev Orig Health Dis. 2020:1-12.

59. Zhang N, Liu S, Shi S, Chen Y, Xu F, Wei X, et al. Solubilization and delivery of Ursolic-acid for modulating tumor microenvironment and regulatory $\mathrm{T}$ cell activities in cancer immunotherapy. J Control Release. 2020;320:168-78.

60. Lim DY, Jeong Y, Tyner AL, Park JH. Induction of cell cycle arrest and apoptosis in HT-29 human colon cancer cells by the dietary compound luteolin. Am J Physiol Gastrointest Liver Physiol. 2007;292(1):G66-75.

61. Ou HC, Pandey S, Hung MY, Huang SH, Hsu PT, Day CH, et al. Luteolin: a natural flavonoid enhances the survival of HUVECs against oxidative stress by modulating AMPK/PKC pathway. Am J Chin Med. 2019;47(3):541-57.

62. Zhang BC, Li Z, Xu W, Xiang CH, Ma YF. Luteolin alleviates NLRP3 inflammasome activation and directs macrophage polarization in lipopolysaccharide-stimulated RAW264.7 cells. Am J Transl Res. 2018;10(1):265-73.

63. Jia Z, Chen A, Wang C, He M, Xu J, Fu H, et al. Amelioration effects of Kaempferol on immune response following chronic intermittent cold-stress. Res Vet Sci. 2019;125:390-6.

64. Li Q, Hu X, Xuan Y, Ying J, Fei Y, Rong J, et al. Kaempferol protects ethanolinduced gastric ulcers in mice via pro-inflammatory cytokines and NO. Acta Biochim Biophys Sin. 2018;50(3):246-53

65. Wu P, Meng X, Zheng H, Zeng Q, Chen T, Wang W, et al. Kaempferol attenuates ROS-induced hemolysis and the molecular mechanism of its induction of apoptosis on bladder cancer. Molecules. 2018;23(10):2592.

66. Mo JS, Choi D, Han YR, Kim N, Jeong HS. Morin has protective potential against ER stress induced apoptosis in renal proximal tubular HK-2 cells. Biomed Pharmacother. 2019;112:108659.

67. Sultana F, Neog MK, Rasool M. Targeted delivery of morin, a dietary bioflavanol encapsulated mannosylated liposomes to the macrophages of adjuvant-induced arthritis rats inhibits inflammatory immune response and osteoclastogenesis. Eur J Pharm Biopharm. 2017;115:229-42.

68. Hyun KH, Gil KC, Kim SG, Sy P, Hwang KW. Delphinidin chloride and its hydrolytic metabolite Gallic acid promote differentiation of regulatory $T$ cells and have an anti-inflammatory effect on the allograft model. J Food Sci. 2019;84(4):920-30.

69. Kang H-M, Park B-S, Kang H-K, Park H-R, Yu S-B, Kim I-R. Delphinidin induces apoptosis and inhibits epithelial-to-mesenchymal transition via the ERK/p38 MAPK-signaling pathway in human osteosarcoma cell lines. Environ Toxicol. 2018;33(6):640-9.

70. Yoon JS, Lee HJ, Chae MK, Lee SY, Lee EJ. Cigarette smoke extract-induced adipogenesis in Graves' orbital fibroblasts is inhibited by quercetin via reduction in oxidative stress. J Endocrinol. 2013;216(2):145-56.

71. Yoon JS, Lee HJ, Choi SH, Chang EJ, Lee SY, Lee EJ. Quercetin inhibits IL1 beta-induced inflammation, hyaluronan production and adipogenesis in orbital fibroblasts from Graves' orbitopathy. PLoS One. 2011;6(10):e26261.

72. Lisi S, Botta R, Lemmi M, Sellari-Franceschini S, Altea MA, Sisti E, et al. Quercetin decreases proliferation of orbital fibroblasts and their release of hyaluronic acid. J Endocrinol Invest. 2011;34(7):521-7.

73. Satari A, Amini SA, Raeisi E, Lemoigne Y, Heidarian E. Synergetic impact of combined 5-fluorouracil and Rutin on apoptosis in PC3 cancer cells through the modulation of P53 gene expression. Adv Pharm Bull. 2019;9(3):462-9.

74. Manzoni AG, Passos DF, da Silva JLG, Bernardes VM, Bremm JM, Jantsch MH, et al. Rutin and curcumin reduce inflammation, triglyceride levels and ADA activity in serum and immune cells in a model of hyperlipidemia. Blood Cells Mol Dis. 2019;76:13-21.

75. Malleda C, Ahalawat N, Gokara M, Subramanyam R. Molecular dynamics simulation studies of betulinic acid with human serum albumin. J Mol Model. 2012;18(6):2589-97.

76. de Castro LL, de Carvalho e Martins Mdo C, Garcez AM, Pacheco JF, Cunha FV, Moita Neto JM, et al. Hypoalbuminemia and oxidative stress in patients on renal hemodialysis program. Nutr Hosp. 2014;30(4):952-9. 
77. Dubois RN, Abramson SB, Crofford L, Gupta RA, Simon LS, Van De Putte LB, et al. Cyclooxygenase in biology and disease. FASEB J. 1998;12(12):1063-73.

78. Konuk EB, Konuk O, Misirlioglu M, Menevse A, Unal M. Expression of cyclooxygenase-2 in orbital fibroadipose connective tissues of Graves' ophthalmopathy patients. Eur J Endocrinol. 2006;155(5):681-5.

79. Vondrichova T, de Capretz A, Parikh H, Frenander C, Asman P, Aberg M, et al. COX-2 and SCD, markers of inflammation and adipogenesis, are related to disease activity in Graves' ophthalmopathy. Thyroid. 2007;17(6): $511-7$.

80. Ishihara K, Hirano T. IL-6 in autoimmune disease and chronic inflammatory proliferative disease. Cytokine Growth Factor Rev. 2002;13(4-5):357-68.

81. Gillespie EF, Raychaudhuri N, Papageorgiou KI, Atkins SJ, Lu Y, Charara LK, et al. Interleukin-6 production in CD40-engaged fibrocytes in thyroidassociated ophthalmopathy: involvement of Akt and NF-kappaB. Invest Ophthalmol Vis Sci. 2012;53(12):7746-53.

82. Luo LH, Li DM, Wang YL, Wang K, Gao LX, Li S, et al. Tim3/galectin-9 alleviates the inflammation of TAO patients via suppressing Akt/NF-kB signaling pathway. Biochem Biophys Res Commun. 2017;491(4):966-72.

83. Kapadia MK, Rubin PA. The emerging use of TNF-alpha inhibitors in orbital inflammatory disease. Int Ophthalmol Clin. 2006;46(2):165-81.

84. Douglas RS, Afifiyan NF, Hwang CJ, Chong K, Haider U, Richards P, et al. Increased generation of fibrocytes in thyroid-associated ophthalmopathy. Clin Endocrinol Metab. 2010;95(1):430-8

85. Li B, Smith TJ. PI3K/AKT pathway mediates induction of IL-1RA by TSH in fibrocytes: modulation by PTEN. J Clin Endocrinol Metab. 2014;99(9):3363-72.

86. Woeller CF, Roztocil E, Hammond C, Feldon SE. TSHR signaling stimulates proliferation through PI3K/Akt and induction of miR-146a and miR-155 in thyroid eye disease orbital fibroblasts. Invest Ophthalmol Vis Sci. 2019; 60(13):4336-45,

87. Kumar S, Nadeem S, Stan MN, Coenen M, Bahn RS. A stimulatory TSH receptor antibody enhances adipogenesis via phosphoinositide 3-kinase activation in orbital preadipocytes from patients with Graves' ophthalmopathy. J Mol Endocrinol. 2011;46(3):155-63.

88. Wang $X-X$, Wang $X-X$, Jia $X-F$, Guo T, Xian T-Z, Liu L, et al. Novel role of SF1 in alleviating thyroid-associated ophthalmopathy through the AMPK/mTOR signaling pathway. Gene. 2019;691:132-40.

89. Zhu J, Zhang W, Zhang Y, Wang Y, Liu M, Liu Y. Effects of Spica prunellae on caspase-3-associated proliferation and apoptosis in human lung cancer cells in vitro. J Cancer Res Ther. 2018;14(4):760-3.

90. Johnson GL. Defining MAPK interactomes. ACS Chem Biol. 2011;6(1):18-20.

91. Verma S, Kesh K, Gupta A, Swarnakar S. An overview of matrix metalloproteinase 9 polymorphism and gastric cancer risk. Asian Pac J Cancer Prev. 2015;16(17):7393-400.

\section{Publisher's Note}

Springer Nature remains neutral with regard to jurisdictional claims in published maps and institutional affiliations.

Ready to submit your research? Choose BMC and benefit from:

- fast, convenient online submission

- thorough peer review by experienced researchers in your field

- rapid publication on acceptance

- support for research data, including large and complex data types

- gold Open Access which fosters wider collaboration and increased citations

- maximum visibility for your research: over $100 \mathrm{M}$ website views per year

At $\mathrm{BMC}$, research is always in progress.

Learn more biomedcentral.com/submissions 